\title{
Sympathy, distress, and prosocial behavior of preschool children in four cultures
}

\author{
Gisela Trommsdorff, Wolfgang Friedlmeier, and Boris Mayer \\ University of Konstanz, Germany
}

\begin{abstract}
This study examined emotional responding (sympathy and distress) and prosocial behavior as well as their relations across four cultures in a specific context. Preschool children $(N=212)$ from two Western cultures, Germany and Israel, and two South-East Asian cultures, Indonesia and Malaysia, participated in this study. Children's emotional reactions and prosocial behavior were observed when interacting with an adult in a quasi-experimental situation. Results showed that children from the two South-East Asian cultures, as compared to children from the two Western cultures, displayed more self-focused distress and less prosocial behavior. Across cultures, a positive relation between sympathy and prosocial behavior and a negative relation between self-focused distress and prosocial behavior were found. The strengths of these relations were moderated by culture. These results are discussed with regard to their cultural meaning in the specific experimental situation as well as to general culture-specific characteristics.
\end{abstract}

Keywords: cross-cultural comparison; distress; observation study; preschool-children; prosocial behavior; sympathy

The importance of sympathy and distress for the development of prosocial behavior and related socialization conditions are well documented in several studies (Eisenberg, 1986; Eisenberg \& Fabes, 1998; Hoffman, 2000; Strayer \& Roberts, 1989; Zahn-Waxler, Radke-Yarrow, \& Wagner, 1992). In general, sympathy fosters prosocial behavior and distress inhibits it (Eisenberg et al., 1989). All these studies were carried out in Western countries. A meta-analysis by Miller, Kozu, and Davis (2001) across various samples from different cultures (14 Western and non-Western countries) demonstrates a positive relation between empathy/sympathy ${ }^{1}$ and prosocial responding in adults and children. However, the authors neither report comparisons of mean differences nor specify which cultural groups and how many samples were included in their analyses. On the basis of this study, no clear conclusion can be drawn regarding the relations between sympathy and prosocial

\footnotetext{
${ }^{1}$ The terms "empathy" and "sympathy" are sometimes used in a synonymous way. Here, we differentiate the two terms - empathy is the vicarious experience of the other's emotional state and further appraisals may lead - in case of perceived negative emotion (like sadness) of the other person - to sympathy or to distress (see also the definition in the section 'Emotional reactions as part of the prosocial process' on p. 286).
}

behavior. Therefore, the main goal of the present study is to test the relations between sympathy/distress and prosocial behavior with children from two Western (Israel and Germany) and two non-Western cultures (Malaysia and Indonesia).

Some researchers argue that a universal human capacity for prosocial emotions and prosocial behavior exists as part of altruism (Hoffmann, 2000; MacDonald, 1984). However, such a universal ability for altruism cannot predict universality of prosocial behavior in different cultural contexts because (1) such behavior includes evaluations based on cultural values, self-construal, and moral beliefs; (2) cultural differences in prosocial behavior are documented (Eisenberg, 1992; Whiting \& Whiting, 1975); and (3) the concept of prosocial behavior consists of a variety of forms that makes a generalization difficult even at the individual level. For example, giving and sharing are two qualities of prosocial behavior that are not primarily evoked by emotional reactions. The display of such prosocial behavior affords a perspective of fairness and equality which implies a more advanced cognitive development (Hoffman, 2000). In the present study, we focus on emotionrelated prosocial behavior (e.g., comforting, helping).

Similar to other studies in this field involving preschoolers, an observational method is used. This method is more
Wolfgang Friedlmeier is now at the Department of Psychology, Grand Valley State University, MI, USA.

Parts of this study were supported by grants from the Deutsche Forschungsgemeinschaft (DFG) to the first author (Tr 169/4-1,2,3). The data collection in Israel was supported by grants from the Lion Foundation Tel Aviv/Konstanz, and the data collection in Malaysia and Indonesia was supported by grants from the University of Konstanz to the first author. We wish to express our gratitude to several colleagues for organizing the data collection at these various places: Arie Nadler in Tel Aviv, Israel; Cecilia Essau in Sarawak/Malaysia; and the late Sri Pidada in Bandung/Indonesia. We thank Rachel Seginer,
Haifa University, and Holly Bunje, University of Minnesota, Twin Cities, for their valuable comments on earlier drafts. We also wish to thank the anonymous reviewers for their suggestions to improve the manuscript.

Correspondence concerning this article should be addressed to Gisela Trommsdorff, Department of Psychology, Post Box D14, University of Konstanz, Germany. Phone: +49(0)7531-88-2917. Fax: +49(0)7531-88-3039. E-mail: Gisela.Trommsdorff@uni-konstanz.de

E-mail addresses of the co-authors: Wolfgang Friedlmeier: friedlmw@gvsu.edu; Boris Mayer: boris.mayer@uni-konstanz.de 
appropriate for this age group, because compared to self-report methods social desirability and self-presentation can be avoided or at least significantly reduced (see Chapman, ZahnWaxler, Cooperman, \& Iannotti, 1987). At this developmental age preschoolers' emotional expression is rather spontaneous and not much affected by display rules like masking or neutralizing (Strayer \& Roberts, 1989) which makes observation studies on emotions more difficult for older age-groups.

The main goal of the present study is to test cultural differences of emotional reactions (sympathy/empathy and distress) and prosocial behavior of preschool children from different cultures in a specific context as well as the relation between emotions and prosocial behavior. Each child participated in a dyadic play-situation and was confronted with the negative emotional reaction (sadness) of a "familiar" young adult play partner. The cause for the play partner's reaction was the loss of her preferred "toy" during her interaction with the child who had been playing with a similar toy. The experimentally induced stimuli should evoke the child's empathy with the play partner's sadness and stimulate prosocial behavior.

Even though these stimuli were the same in all cultural groups, they may evoke different emotions and related behavior (e.g., Markus \& Kitayama, 1994; Mesquita, Frijda, \& Scherer, 1997; Mesquita \& Markus, 2004) due to culturespecific meanings given to the situation. For example, a similar observation study with 2-year-old German and Japanese girls with an adult play partner, in which their mothers were present, showed that Japanese as compared to German girls expressed more distress and were less able to regulate their distress reaction (Friedlmeier \& Trommsdorff, 1999). These culture-specific results can be interpreted as the consequence of different socialization beliefs and practices. German mothers as compared to Japanese mothers emphasize early independence. Thus, the German 2-year-olds were more able to regulate their distress by actively seeking maternal support. Based on these results, individual- versus social-oriented value orientations (and related socialization practices) may serve as a general framework of culturespecific differences.

\section{Cultural groups and their characteristics}

We chose samples from Indonesia (West Java), Malaysia (Borneo, Sarawak), Israel, and Germany for the cross-cultural comparisons. We assume that there are more cultural similarities than differences with respect to psychologically relevant variables between the two Western and the two South-East Asian cultural samples, respectively. The Israeli and German urban areas are rather similar in respect to technological and economic advancement and related development of urbanization and family structure; both cultures share Western individualistic values of autonomy and independence (for Israel see Schwartz, Struch, \& Bilsky, 1990; for Germany see Hofstede, 2000; Inglehart, 1990). In contrast, the Indonesian and Malaysian cultures (both including several ethnic groups) share similarities with respect to religion (Islam), economic, and technological development (low urbanization), and widely held non-Western values of social orientation, relatedness, and "symbiotic harmony" (Rothbaum, Pott, Azuma, Miyake, \& Weisz, 2000) (for Indonesia, especially Java, see MagnisSuseno, 1997; Mulder, 1992; for Malaysia, especially Sarawak, see Essau, 1992; Essau \& Trommsdorff, 1996). These differences are also reflected in the cultural dimension of "individualism-collectivism" (IC). According to a study on 53 countries (Hofstede, 2001), Indonesia and Malaysia are more collectivistic (rank 47-48 and 36, respectively) than Germany and Israel, which represent more individualistic societies (ranking at positions 15 and 19, respectively).

In line with the recent critical debate on individualism and collectivism (e.g., Kağıtçıbașı, 2005; Oyserman, Coon, \& Kemmelmeier, 2002), we do not conceive of these constructs as poles of one dimension; instead we conceive of these as encompassing a complex of relevant psychological phenomena including the predominance of independent versus interdependent person-environment relations (Markus \& Kitayama, 1991), and related developmental pathways (Rogoff, 2003; Rothbaum et al., 2000; Trommsdorff, 2006b). We chose these four cultural groups by assuming that they differ from each other with respect to basic cultural value orientations to which we refer here as "individual-oriented" (for Germany and Israel) and "social-oriented" (for Indonesia and Malaysia). Individual-oriented values include the value of individuality, independence, autonomy, and self-realization, with the focus on the person him/herself; social-oriented values include the value of interdependence, relatedness, and loyalty to the group with the focus on group connectedness (e.g., Matsumoto, 2000; Triandis, 1995). Cultural values represent constraints as well as opportunities for human adaptation to the environment and individual development. They also represent guidelines for parental goals and practices and thereby affect children's emotional and prosocial development more or less directly. Parents as main socialization agents (beside other relatives, siblings, teachers, peers) transmit cultural values and knowledge to their children neither in a random nor in a uniform or deterministic way (e.g., Super \& Harkness, 1997; Trommsdorff, in press). The children's internalization of these values and related behavior depends on various culture-specific socialization processes. Thus, children's development is influenced by socialization processes in the specific cultural context.

\section{Cultural context influencing emotional reactions and prosocial behavior}

\section{Prosocial behavior}

Prosocial behavior is defined here as voluntary behavior intended to benefit another person (Staub, 1979). "Voluntary" emphasizes the spontaneous initiative by the actor in contrast to professional help (e.g., physicians or nurses). Prosocial behavior may include helping, sharing, giving, and comforting (see Bierhoff, 2002).

We focus on emotion-evoked spontaneous prosocial behavior without explicit request. When confronted with the misfortune of another person, one may want to change the negative (emotional) state of the other person so that he or she feels better. This goal can be achieved either by behavior which is directly related to the problem such as offering compensation, giving advice, and attempting to remove or alter the circumstances of the misfortune, or by focusing on the other person's emotions and comforting the person verbally or physically (Friedlmeier, 1996; Staub, 1979; Whiting \& Whiting, 1975). Since prosocial behavior is a heterogeneous concept it 
may include various kinds of behavior which may be based on different motivations (Persson, 2005; Trommsdorff, 2005). Not to act at all with respect to the concerned person may also be a possible reaction based on prosocial values (e.g., to save the person's face in cultures where the expression of emotions is discouraged). However, non-acting is regarded here as refraining from helping behavior, because non-acting is arbitrary, i.e., such behavior has different meanings depending on the motivation of the person; this is difficult to be differentiated in our observational design. Children's prosocial behavior develops through guidance and modeling by parents and other socialization agents who influence the children's active interpretation of cultural values and expectations, the internalization of prosocial values and the children's development of moral reasoning (Eisenberg, 1995).

In individual-oriented cultures, the value of individual agency and autonomy may give rise to earlier self-efficacy and competence by actively engaging in prosocial behavior, while, in social-oriented cultures, the display of prosocial behavior may depend more on situation-specific social obligations and on duty (e.g., Miller, 1997). Children from social-oriented cultures may show less prosocial behavior in the case of an asymmetric interaction with an adult, as compared to children from individual-oriented cultures. However, it cannot be excluded that less overt prosocial behavior may nevertheless reflect prosocial motivation as discussed above (Persson, 2005).

\section{Emotional reactions as part of the prosocial process}

The experience of another person's mishap evokes emotional reactions (e.g., empathy) which may promote prosocial behavior (Zahn-Waxler et al., 1992). Empathy can be defined as the vicarious experience of another person's emotional state; that is, the person experiences an emotion similar to the other person's emotional reaction while being aware that this feeling is caused by the other person's situation (e.g., Eisenberg, 1986; Eisenberg \& Fabes, 1998; Friedlmeier, 1993, 1996, 2003; Trommsdorff, 1995).

Empathy may induce sympathy, a feeling of sorrow and concern for the other person in need (Eisenberg, 1986; Friedlmeier, 1993). Empathy, however, may also induce distress, an aversive emotional reaction when experiencing the other person's mishap.

Distress can be differentiated with regard to its quality. In our previous studies based on children's behavior in quasinatural situations we differentiated two qualities of distress: self-focused distress and other-focused distress (Friedlmeier, 1993, with German boys in middle childhood; Kienbaum, 1993, with Russian and German preschool children; Kobayashi, 1995, and Trommsdorff, 1995, with Japanese and German children). Self-focused distress, characterized by shifting the attention away from the victim, arises when the child feels empathy with the victim and at the same time feels uneasy and irritated. The related attempt to avoid the situation can serve as a coping strategy to reduce one's own discomfort (Young, Fox, \& Zahn-Waxler, 1999). In contrast, other-focused distress involves empathy with the victim and the feeling with the victim gives rise to distress while focusing one's attention more on the victim. Other-focused distress can be characterized by an approach-oriented reaction, and self-focused distress by an avoidant reaction.

The experience of sympathy can be seen as an emotional ability that develops in early childhood, primarily in interaction with the caregivers, while peers, teachers, and other socialization agents are also relevant in the development of children's sympathy. The caregivers' sensitivity enhances the development of sympathy. At first glance, one may expect that children from social-oriented as compared to children from individual-oriented cultures experience more sympathy; empathy is often promoted more in social-oriented cultures which value interdependence highly and which provide a developmental path for empathic feeling with the other (Mesquita \& Markus, 2004; Rothbaum \& Trommsdorff, 2007; Trommsdorff, 2006a, b). At the same time, self-guided emotion regulation develops later due to the stronger focus on interdependence. Children who cannot adequately regulate their emotions tend to become over-aroused and experience distress in response to another person's misfortune. Therefore, if differences occur, Malaysian and Indonesian children are expected to display stronger distress reactions compared to German and Israeli children.

\section{Relations between emotional reactions and prosocial behavior}

Studies in Western countries have shown that emotional contagion (Zahn-Waxler, Radke-Yarrow, \& Wagner, 1992) and emotional reactions like sympathy in case of perceived distress of another person can activate prosocial behavior in very young children (18 to 24 months of age) (Bischof-Köhler, 1991; Zahn-Waxler, Radke-Yarrow, \& King, 1979). In metaanalyses, several studies have shown that sympathy promotes prosocial behavior in young children (reviews by Eisenberg \& Fabes, 1998; Staub, 1979). Low to moderate relations between empathy and prosocial behavior were found by Eisenberg and Miller (1987).

The function of distress for prosocial behavior is less clear. Under the condition of low-cost behavior directed toward known individuals, sympathy is positively related and distress is negatively related to prosocial behavior in children and even in infants. However, situational conditions moderate the effects of emotional reactions such as distress on prosocial behavior (for a review see Eisenberg \& Fabes, 1998).

It is additionally an open question as to whether the two above mentioned forms of distress have different functional relations with prosocial behavior. Self-focused distress may inhibit prosocial behavior because the child tries to avoid the situation instead of helping. In contrast, other-focused distress may inhibit prosocial behavior due to a lack of self-efficacy, i.e., the child is oriented to the adult victim but cannot find an appropriate way to initiate prosocial behavior.

To conclude, a universal positive relationship between sympathy and prosocial behavior and a negative relationship between distress and prosocial behavior can be expected. These relations are affected by different appraisals regarding the play partner's situation in social-oriented cultures as compared to individual-oriented cultures. For example, children from social-oriented cultures may be less inclined to follow their sympathetic feelings with the victim by displaying prosocial behavior spontaneously due to social norms restricting such behavior in certain situations.

We do not focus on the gender issue here. As gender differences with regard to emotional reactions and prosocial behavior might occur we include an explorative research question about gender. 


\section{Summary of research questions}

1 Do Malaysian and Indonesian children (social-oriented cultures) differ in prosocial behavior compared to German and Israeli children (individual-oriented cultures)?

2 Do Malaysian and Indonesian children differ in sympathy compared to German and Israeli children, and do the former differ in other-focused and/or self-focused distress?

3 Is the relation between sympathy/distress and prosocial behavior the same for Malaysian and Indonesian children compared to German and Israeli children?

4 Are there gender differences and are they related to specific cultural groups?

\section{Method}

\section{Participants}

A total of 212 five-year-old children (118 girls) from Germany, Israel, Indonesia, and Malaysia participated in this study. The German sample was selected from Konstanz, a mid-sized town in Southern Germany ( $n=36$ girls and $n=24$ boys); the Israeli sample was selected from a kindergarten of Israeli Jewish children from Haifa, a city in a central region of Israel $(n=27$ girls and $n=25$ boys); the Indonesian sample was selected from a city kindergarten in Bandung, West Java $(n=31$ girls and $n=25$ boys), and the Malaysian sample (Iban) from a middle size town in Sarawak, the Malaysian part of Borneo ( $n=24$ girls and $n=20$ boys). All samples were homogeneous with regard to ethnicity and SES. All children came from middle-class families with highly educated parents.

\section{Instruments and cross-cultural comparability}

We designed an observational study that allowed videotaping the child's emotional reactions and prosocial behavior in a quasi-natural setting with a play partner. The experimental situation was prepared with cooperating developmental psychologists from the four cultures in order to reach agreement about the cultural applicability of this procedure. All four play partners were young female university students (about 18 to 20 years of age). Several pretests in each cultural group were carried out in order to train the play partners for their role by giving feedback to the videotaped pretests, and to test the technical procedure of using two cameras. The Malaysian and Israeli play partners were trained at the University of Konstanz and the Indonesian play partner was trained by German researchers who stayed in Bandung to carry out the cooperation study there. In all four cultural groups, the play partner was instructed to control her behavior such that she displayed the same behavior consistently over all trials and at the same time to take into account the behavioral reactions of the child to a moderate degree. The individual personality of the play partner should thus be second to the role she had to perform. A further aim was to create some familiarity between the child and the play partner before the experiments started. For reasons of comparability, these stimuli and situations were held constant in all four cultures (see procedure) although we are aware that children from different cultures may interpret the situation in a culture-specific way.

\section{Procedure: The balloon-game situation}

The experiment took place in a separate room in each of the kindergartens. In order to become familiar with the child, the play partner and the child met for the first time in the kindergarten group. Then, both played together in a separate room for about 30 minutes. At the end of this session, the play partner announced that she would bring balloons for the next play session. At the next meeting (some days later), the participant child and the play partner played together for about 15 minutes (warm-up). After this play session the play partner started the "balloon-game" by changing two colored balloons into balloon dolls. They painted and dressed their own balloon dolls, gave faces and names to them, and had the dolls play with each other. The child was asked whether she or he would like to build a tower for the dolls. When the players were relaxed and happy the play partner secretly popped her balloon while the child was concentrating on the tower and could not be aware of her manipulation. She commented in a sad voice that her balloon had popped and that she was very sad about this. Covering her face with her hands and sighing, she fell into a state of sorrow for about two minutes. After that, the play partner continued to play with the child in a cheerful and relaxed manner for another couple of minutes. In the end, the child received a gift. This sequence was videotaped in all cultures by two hidden cameras, one focusing on the total scene and one on the child's face. The whole session lasted about 40 minutes.

\section{Measures}

Children's emotional reactions and prosocial behavior were coded by two independent raters during the time span from the play partner's misfortune (popped balloon) until the end of the play partner's sorrow (about two minutes). This time span has proven sufficient in pretests to evoke children's emotional reactions and various kinds of behavior; it also has proven sufficient for the researchers to code the theoretically relevant observations from the video tapes. The raters were members of the respective cultural groups. As all raters were able to speak German, no translation of the coding schemes was necessary. After a translation of the verbal communications in the play situation into English by the team members from the respective cultures, additional German raters coded one third of each sample in order to test inter-rater reliability. Raters never coded both emotional reactions and prosocial behavior in order to allow for independent ratings of the two constructs. The coding took several months since repeatedly looking at the tapes in order to adequately interpret and understand the children's behavior was necessary before the coding scheme and the actual coding could be finalized.

Emotional reactions. Three emotional reactions were assessed: sympathy, other-focused distress, and self-focused distress. These three emotional reactions were rated on 6-point scales from $0=$ no emotional reaction to $5=$ very strong emotional reaction according to the extent of emotional expression. Scoring was based on the following criteria:

1 Sympathy. The mimic reaction shows features of sadness (e.g., the corners of the mouth are lowered and the inner eye brows are lifted, leaving the lower part of the face relaxed), no irritated features in gestures are expressed (Eisenberg et al., 1989), no signs of tension occur, and the voice is soft. 
2 Other-focused distress. The child shows signs of bodily tension (e.g., lower part of the face is tense and lips are pressed together) and/or irritated gestures, but stays focused on the play partner and concentrates on her misfortune.

3 Self-focused distress. The child also shows signs of tension but in contrast to other-focused distress he or she turns away from the play partner; we interpreted this behavior as avoidance of the distressing stimuli (the other person's negative emotions).

The inter-rater reliability reached satisfying levels of agreement to ensure reliable coding in all four cultural groups. For emotional reactions, all Pearson correlation coefficients were highly significant. The mean reliability coefficient was $r=.90$ with a range of $r=.81$ (sympathy for Malaysian children) to $r=.96$ (other-focused distress for Indonesian children). Additionally, weighted kappa (Cohen, 1968) was calculated to check the extent of agreement between raters. The mean coefficient was $\kappa_{\mathrm{w}}=.73$ with a range of $\kappa_{\mathrm{w}}=.61$ (sympathy for Malaysian children) to $\kappa_{\mathrm{w}}=.91$ (sympathy for Indonesian children) indicating fair to almost perfect agreement between raters (Banerjee \& Fielding, 1997). All weighted kappacoefficients were significant at the $p<.01$ level.

Prosocial behavior. Extent of prosocial behavior was rated on a 6-point scale ranging from $0=$ no prosocial behavior to $5=$ high intensity prosocial behavior. When the child gave brief advice to the adult play partner but did not actually help the play partner, low intensity of prosocial behavior (1) was rated; if the child tried to help the play partner a great deal, for instance by looking around for another balloon or offering his or her own balloon, high intensity of prosocial behavior (5) was rated. The mean reliability coefficient was $r=.96$ with a range of $r=.90$ (German children) to $r=1.00$ (Malaysian children). The mean coefficient of the weighted kappas was $\kappa_{\mathrm{w}}=.90$ with a range of $\kappa_{\mathrm{w}}=.77$ (German children) to $\kappa_{\mathrm{w}}=1.00$ (Malaysian children).

To ensure the validity of our measure of prosocial behavior we cross-validated it with two other measures derived from an event-sampling of all prosocial behaviors displayed. The observed prosocial behaviors were helping (e.g., by providing own balloon), giving advice (e.g., how to get a new balloon), and comforting/consoling the partner (verbally or physically). The sum of all initiated prosocial acts that appeared during the two minutes of observation indicates the persistence of prosocial behavior. If a specific prosocial behavior was displayed several times during the experimental sequence, this was counted as novel occurrences only if a minimum delay of five seconds had elapsed since the previous occurrence. The variability of prosocial behavior, defined as the sum of all qualitatively different prosocial behaviors displayed, was our second measure for cross-validation. Across the four cultures, the mean correlation between our main measure, the extent or intensity of prosocial behavior, and the persistence of prosocial behavior was $r=.71$, and the mean correlation between intensity of prosocial behavior and the variability of prosocial behavior was $r=.80$. Correlations ranged between $r=.42$ and $r=.90$ and were all significant at the $p<.01$ level. On the basis of these analyses we concluded that our measure of prosocial behavior used in the following analyses is a valid indicator of the prosocial behavior the children displayed in all four cultures. These variables are all based on the video-taped observation of children's behavior which was coded according to the theoretically derived coding scheme as described above.

\section{Results}

\section{Cultural and gender differences in emotional reactions}

To analyze cultural and gender differences in emotional reactions two-way ANOVAs with the factors Culture and Gender were computed for each emotional reaction. An alphalevel of .05 was set for all analyses.

Sympathy. Results yielded no significant main effects but a significant Culture $\times$ Gender interaction (see Table 1). Posthoc comparisons showed that in Germany, boys expressed significantly less sympathy than girls while there were no gender differences in the other cultures (see Figure 1). Furthermore, German girls were significantly higher in sympathy than boys and girls from Israel and Indonesia.

Other-focused distress. Again, no significant main effects but a significant interaction effect resulted for other-focused distress (see Table 1). Here, a significant gender difference only occurred for Malaysian children with boys showing more distress than girls (see Figure 1).

Self-focused distress. A significant main effect of culture and a significant interaction effect resulted for self-focused distress (see Table 1). Children from Germany and Israel expressed significantly less self-focused distress than children from Indonesia and Malaysia with the exception of German boys who were not different from their Indonesian and Malaysian peers (see Figure 1).

Additional MANOVAs were computed to compare the extent of the three emotional reactions within each culture. Significant differences occurred in all four cultures (Germany: Wilk's $\lambda=.74, p<.01$; Israel: Wilk's $\lambda=.53, p<.01$; Indonesia: Wilk's $\lambda=.51, p<.01$; Malaysia: Wilk's $\lambda=.77, p<.01$ ). Single comparisons showed that other-focused distress was the strongest reaction in all four cultural groups (see Table 1). The strength of expression was significantly higher than sympathy and also significantly higher than self-focused distress in all cultures except Malaysia, where the two forms of distress did not differ. Sympathy was significantly higher than self-focused distress in Israel, marginally significantly higher in Germany, no difference resulted in Malaysia, and sympathy was significantly lower than self-focused distress in Indonesia.

\section{Cultural and gender differences in prosocial behavior}

A significant main effect of Culture resulted in the ANOVA for prosocial behavior (see Table 1). German and Israeli children showed significantly more prosocial behavior than children from Indonesia and Malaysia. Additionally, there was a marginally significant gender main effect $(p=.05)$ such that boys showed lower intensity of prosocial behavior than girls (see Figure 1).

\section{Relations between emotional reactions and prosocial behavior: Correlation analysis}

As a first step to analyze the relations among emotional reactions and prosocial behavior, we conducted bivariate correlations. Fisher's $z$-tests used to examine gender-specific differences in the respective correlations of boys and girls revealed that none of the correlations were significantly 
Table 1

Mean scores and standard deviations for prosocial behavior and emotional reactions

\begin{tabular}{|c|c|c|c|c|c|c|c|c|c|c|c|}
\hline & \multicolumn{4}{|c|}{ Individual-oriented cultures } & \multicolumn{4}{|c|}{ Social-oriented cultures } & \multirow{3}{*}{\multicolumn{2}{|c|}{ ANOVA F }} & \\
\hline & \multicolumn{2}{|c|}{ Germany } & \multicolumn{2}{|c|}{ Israel } & \multicolumn{2}{|c|}{ Indonesia } & \multicolumn{2}{|c|}{ Malaysia } & & & \\
\hline & Boys & Girls & Boys & Girls & Boys & Girls & Boys & Girls & & & \\
\hline & $\begin{array}{c}M \\
(S D)\end{array}$ & $\begin{array}{c}M \\
(S D)\end{array}$ & $\begin{array}{c}M \\
(S D)\end{array}$ & $\begin{array}{c}M \\
(S D)\end{array}$ & $\begin{array}{c}M \\
(S D)\end{array}$ & $\begin{array}{c}M \\
(S D)\end{array}$ & $\begin{array}{c}M \\
(S D)\end{array}$ & $\begin{array}{c}M \\
(S D)\end{array}$ & $\begin{array}{l}\text { Culture }(C) \\
(d f=3,206)\end{array}$ & $\begin{array}{l}\text { Gender }(G) \\
(d f=1,208)\end{array}$ & $\begin{array}{c}C \times G \\
(d f=3,206)\end{array}$ \\
\hline Sympathy $^{\dagger}$ & $\begin{array}{r}0.88_{\mathrm{a}} \\
(1.26)\end{array}$ & $\begin{array}{r}2.22_{\mathrm{c}} \\
(1.40)\end{array}$ & $\begin{array}{l}1.24_{\mathrm{ab}} \\
(1.39)\end{array}$ & $\begin{array}{l}1.40_{\mathrm{ab}} \\
(1.66)\end{array}$ & $\begin{array}{l}1.17_{\mathrm{ab}} \\
(1.20)\end{array}$ & $\begin{array}{l}1.45_{\mathrm{ab}} \\
(1.59)\end{array}$ & $\begin{array}{l}2.00_{\mathrm{bc}} \\
(1.38)\end{array}$ & $\begin{array}{l}1.75_{\mathrm{bc}} \\
(1.67)\end{array}$ & 1.55 & $3.55^{+}$ & $2.88^{\star}$ \\
\hline Other-focused distress ${ }^{\dagger}$ & $\begin{array}{l}2.38_{\mathrm{ab}} \\
(1.81)\end{array}$ & $\begin{array}{r}2.28_{\mathrm{a}} \\
(1.43)\end{array}$ & $\begin{array}{r}2.16_{\mathrm{a}} \\
(1.70)\end{array}$ & $\begin{array}{l}2.76_{\mathrm{abc}} \\
(1.74)\end{array}$ & $\begin{array}{l}2.50_{\mathrm{ab}} \\
(1.47)\end{array}$ & $\begin{array}{l}3.19_{\mathrm{bc}} \\
(1.17)\end{array}$ & $\begin{array}{r}3.65_{\mathrm{c}} \\
(1.46)\end{array}$ & $\begin{array}{l}2.46_{\mathrm{ab}} \\
(1.61)\end{array}$ & $2.38^{+}$ & 0.00 & $3.70^{\star}$ \\
\hline Self-focused distress ${ }^{\dagger}$ & $\begin{array}{r}1.92_{\mathrm{a}} \\
(1.64)\end{array}$ & $\begin{array}{r}0.61_{\mathrm{a}} \\
(1.15)\end{array}$ & $\begin{array}{r}0.33_{\mathrm{a}} \\
(1.01)\end{array}$ & $\begin{array}{r}0.72 \mathrm{a} \\
(1.17)\end{array}$ & $\begin{array}{c}2.63_{\mathrm{b}} \\
(1.44)\end{array}$ & $\begin{array}{c}1.90_{\mathrm{b}} \\
(1.11)\end{array}$ & $\begin{array}{r}2.30_{\mathrm{b}} \\
(1.84)\end{array}$ & $\begin{array}{c}2.46_{\mathrm{b}} \\
(1.82)\end{array}$ & $19.40^{\star \star}$ & $3.56+$ & $4.13^{\star \star}$ \\
\hline Prosocial behavior ${ }^{\dagger \dagger}$ & $\begin{array}{c}1.58 \\
(1.50)\end{array}$ & $\begin{array}{c}2.39 \\
(1.79)\end{array}$ & $\begin{array}{c}2.04 \\
(1.88)\end{array}$ & $\begin{array}{c}2.31 \\
(1.87)\end{array}$ & $\begin{array}{c}0.38 \\
(1.01)\end{array}$ & $\begin{array}{c}1.00 \\
(1.65)\end{array}$ & $\begin{array}{c}0.25 \\
(0.79)\end{array}$ & $\begin{array}{c}0.21 \\
(0.72)\end{array}$ & $19.68^{\star \star}$ & $3.79+$ & 0.76 \\
\hline
\end{tabular}

Note. Means in one row that share subscripts did not differ significantly in least-square mean tests (reported only for analyses with a significant interaction effect). $t_{0}=$ no emotional reaction $-5=$ very strong emotional reaction. $t^{t} 0=$ no prosocial behavior $-5=$ very intensive prosocial behavior.
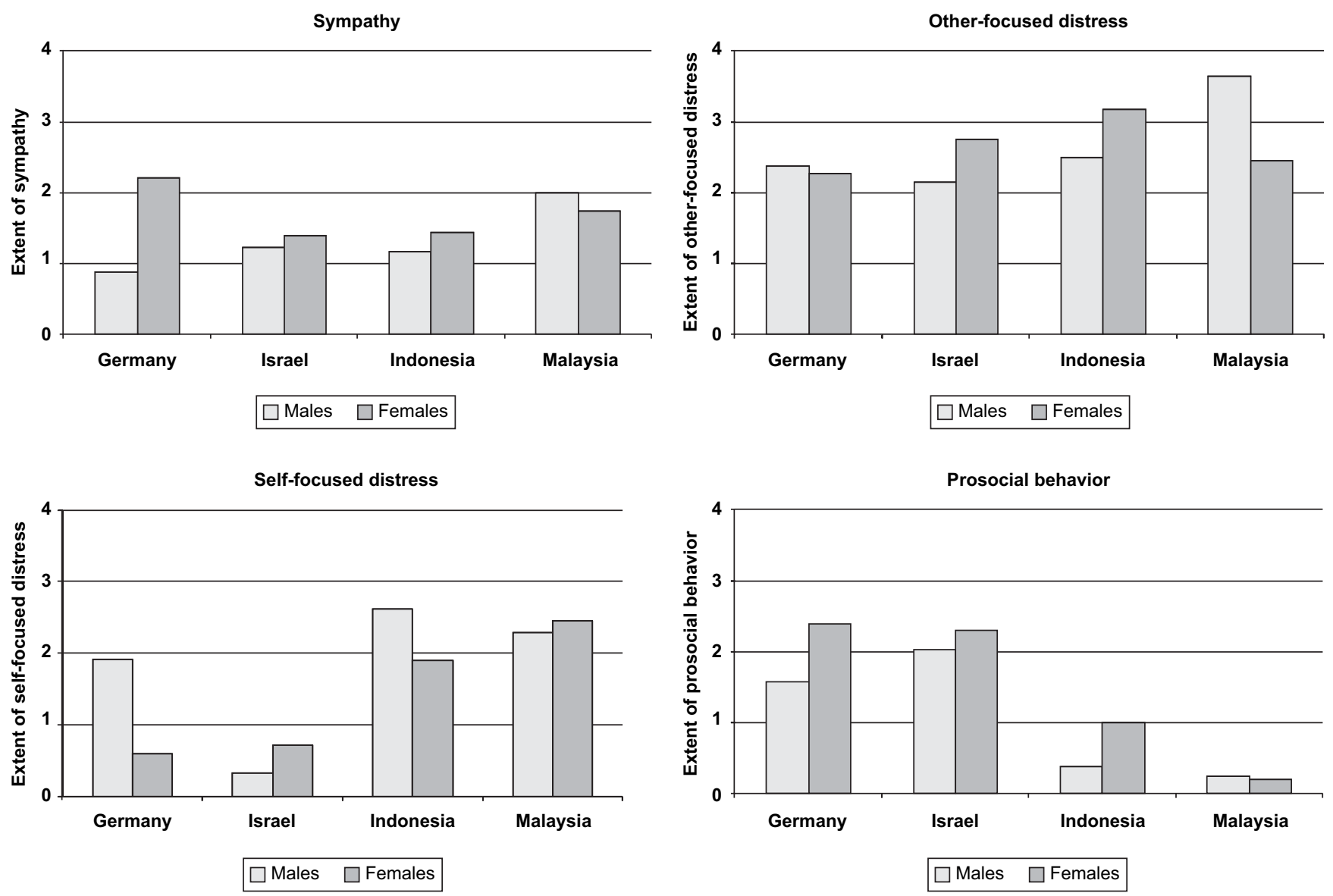

Figure 1. Cultural and gender differences on sympathy, other-focused distress, self-focused distress, and prosocial behavior.

different. Therefore, we report the correlations for the combined samples of boys and girls for each culture.

Results showed that sympathy and prosocial behavior were significantly positively correlated in all four cultures (Germany: $r(58)=.53, p<.01$; Israel: $r(50)=.72, p<.01$; Indonesia: $r(54)=.45, p<.01$; Malaysia: $r(42)=.37, p<.05$ ), and selffocused distress was significantly negatively correlated with prosocial behavior in all cultures (Germany: $r(58)=-.41$, 
$p<.01$; Israel: $r(50)=-.37, p<.01$; Indonesia: $r(54)=-.49$, $p<.01$ ) except Malaysia, $r(42)=-.22$, ns. No significant correlations were obtained for the relation between other-focused distress and prosocial behavior (Germany: $r(58)=-.15$, ns; Israel: $r(50)=-.20$, ns; Indonesia: $r(54)=.24$, ns; Malaysia: $r(42)=.02, \mathrm{~ns})$.

\section{Relations between emotional reactions and prosocial behavior: Regression analysis}

As the three emotional reactions were partly interrelated, we computed regression analyses in order to obtain the net effects of each of the children's emotional reactions on their prosocial behavior. Analyses carried out to compare the beta-weights for the gender-specific subsamples within each of the cultural groups showed no significant Gender $\times$ Emotional Reaction interaction effects. Therefore, similar to the correlation analysis above, we focused on an analysis of the full sample in each culture (see Table 2). For the combined samples of boys and girls, significant overall effects were found for Germany, Israel, and Indonesia, but not for Malaysia. Sympathy was significantly positively related to prosocial behavior in Germany and Israel, and at trend levels in Indonesia. The single effect of sympathy was also significant in Malaysia though the overall analysis was non-significant in this culture. The only further significant effect was a negative effect of self-focused distress on prosocial behavior in Indonesia; this effect was at trend levels in Germany and Israel.

In order to compare the culture-specific regression coefficients we applied a General Linear Model (GLM)-framework including interaction terms of culture with each of the three emotional reactions variables. Results showed that the regression effects of sympathy on prosocial behavior were significantly different across cultures, $F_{\text {Culture }} \times$ Sympathy $(3,198)=$ $7.30, p<.01$, as well as the regression effects of self-focused distress, $F_{\text {Culture }} \times$ Self-focused Distress $(3,198)=3.74, p<.05$. No significant interaction effect occurred for other-focused distress, $F_{\text {Culture }} \times$ Other-focused Distress $(3,198)=0.77, p=.55$, indicating no cross-cultural differences regarding the effect of other-focused distress on prosocial behavior.

Contrast analyses for the significant interaction effects showed that the effect of sympathy on prosocial behavior was significantly stronger in Israel $(B=.82)$ than in Germany $(B=$ $\left..49, F_{\text {Dif }}=4.49, p<.05\right)$, Indonesia $\left(B=.26, F_{\text {Dif }}=8.01, p<\right.$ $.05)$, and Malaysia $\left(B=.18, F_{\text {Dif }}=21.22, p<.01\right)$. Additionally, the effect of sympathy was stronger in Germany $(B=.49)$ than in Malaysia $\left(B=.18, F_{\text {Dif }}=7.82, p<.01\right)$.

The negative effect of self-focused distress on prosocial behavior was significantly weaker in Malaysia $(B=-.01)$ than in Indonesia $\left(B=-.38, F_{\text {Dif }}=5.86, p<.05\right)$, Israel $(B=-.30$, $\left.F_{\text {Dif }}=7.79, p<.01\right)$, and Germany $\left(B=-.25, F_{\text {Dif }}=5.88\right.$, $p<.05)$.

\section{Discussion}

This cross-cultural study aimed to investigate preschoolers' emotional reactions and prosocial behavior during a mishap of an adult play partner in a play situation. Cultural differences and similarities were found with regard to the extent of children's emotional reactions, their prosocial behavior, and the relations between both. Some reasons for these similarities and differences are discussed by referring to the theoretical framework of cultural values and the related developmental pathways (Rothbaum et al., 2000; Super \& Harkness, 1997). This framework may help to specify the cultural meaning that children give to this specific situation.

Prosocial behavior. German and Israeli children displayed more prosocial behavior as compared to Indonesian and Malaysian children in the experimental situation. The difference could be due to less ability and experience to help, and less self-efficacy to help effectively. Alternative explanations may be more applicable, especially the relative difference in

Table 2

Multiple regression analyses with emotional reactions predicting prosocial behavior in four cultures

\begin{tabular}{|c|c|c|c|c|c|c|}
\hline & \multicolumn{6}{|c|}{ Prosocial behavior } \\
\hline & $\mathrm{B}$ & $S E \mathrm{~B}$ & $\beta$ & $d f$ & $\mathrm{~F}$ & $\mathrm{R}^{2}$ \\
\hline \multicolumn{7}{|l|}{ Germany } \\
\hline Sympathy & 0.49 & 0.14 & $0.42^{\star \star}$ & 3,56 & $9.15^{\star \star}$ & .33 \\
\hline Other-focused distress & -0.10 & 0.12 & -0.09 & & & \\
\hline Self-focused distress & -0.25 & 0.14 & $-0.22^{+}$ & & & \\
\hline \multicolumn{7}{|l|}{ Israel } \\
\hline Sympathy & 0.82 & 0.12 & $0.67^{\star \star}$ & 3,50 & $21.08^{\star \star \star}$ & .58 \\
\hline Other-focused distress & -0.20 & 0.10 & $-0.18^{+}$ & & & \\
\hline Self-focused distress & -0.30 & 0.17 & $-0.18^{+}$ & & & \\
\hline \multicolumn{7}{|l|}{ Indonesia } \\
\hline Sympathy & 0.26 & 0.14 & $0.26^{+}$ & 3,51 & $6.98^{\star \star}$ & .29 \\
\hline Other-focused distress & 0.02 & 0.14 & 0.02 & & & \\
\hline Self-focused distress & -0.38 & 0.16 & $-0.35^{\star}$ & & & \\
\hline \multicolumn{7}{|l|}{ Malaysia } \\
\hline Sympathy & 0.18 & 0.09 & $0.36^{\star}$ & 3,40 & 2.16 & .14 \\
\hline Other-focused distress & -0.01 & 0.07 & -0.03 & & & \\
\hline Self-focused distress & -0.01 & 0.08 & -0.03 & & & \\
\hline
\end{tabular}

${ }^{+} p<.10 ;{ }^{\star} p<.05 ;{ }^{\star \star} p<.01$. 
status between the child and the victim, which may affect the extent of prosocial behavior. Western children are socialized in a context where asymmetric hierarchical relations are less pronounced and independence, self-reliance, self-efficacy, and taking initiative are valued. Thus, children initiate prosocial behavior when they perceive another person in need regardless of the person's familiarity and status (as an adult). In contrast, in a culture which promotes interdependence and respect for hierarchical relations, children may refrain from initiating prosocial behavior, especially when face-saving values are implied. Face-saving behavior is more important in social- as compared to individual-oriented cultures (Triandis, 1995). Therefore, ignoring the mishap of another person (especially an authority figure) can be more valued than attempting to help and thereby risking that the other person loses face. However, it is not clear whether face-saving strategies have already been developed at this age. Furthermore, "not acting" could not be adequately interpreted in our observational study; it is presumably based on different motivations, especially when observed in a distressing situation.

The low amount of prosocial behavior of Malaysian and Indonesian children does not necessarily imply that these children generally show less prosocial behavior since we only studied one specific condition. Other studies have reported high rates of prosocial behavior in reference to family duties for children from social-oriented countries (Whiting \& Whiting, 1975). Different results can be expected when varying the experimental situation by asking the child directly for help (prosocial behavior on request). Eisenberg, McCreath, and Ahn (1988) report a positive relation between distress and compliant sharing in a play situation with a peer for a U.S. sample. In a situation which is more clearly structured for the child with regard to the victim's expectations, children from the two South-East Asian cultures may have engaged even more in helping behavior than children from the two Western cultures. Asking for help directly may frame the situation for the child differently; such a request rather evokes social responsibility and a feeling of obligation, and thereby reduces distress and the inhibition of prosocial behavior. Future studies may investigate domain-specific contexts of prosocial behavior and test whether reverse effects can be found under specific conditions.

Emotional reactions. No cultural differences in sympathy occurred with a relatively low occurrence of sympathy for all groups. Other-focused distress was relatively high among the samples and also not subject to cultural differences. The situation of the adult victim seems to have induced most of the preschool children to feel uneasy without turning their attention away from the victim. This may indicate that the situation has induced strong distress reactions and was not easy for the children to handle. Therefore, we should caution to generalize on the children's ability of emotion regulation and also on the children's sympathy. Significant cultural differences did occur for self-focused distress. Children from the two social-oriented cultures (Indonesia and Malaysia) showed higher self-focused distress than children from the two individual-oriented cultures (Germany and Israel). The stronger self-focused distress could be the result of a higher over-arousal in the Malaysian and Indonesian children due to culturally-based differences in "shyness" with adults; inhibited behavior seems to be more accepted (less negatively valued) in South-East Asian cultures than in the West (for Indonesia cf. Eisenberg, Liew, \& Pidada, 2004).
Relations between emotional reactions and prosocial behavior. A positive relation between sympathy and prosocial behavior and a negative relation between self-focused distress and prosocial behavior (here except for Malaysian children) was found in all four cultures; other-focused distress had no significant effects on prosocial behavior. The regression analyses demonstrated that sympathy was the strongest predictor for prosocial behavior; self-focused distress only had a weak negative effect. The results on the positive relation between sympathy and prosocial behavior are in line with many studies in Western cultures (for an overview see Eisenberg \& Fabes, 1998). At the same time, the strength of the relation was moderated by culture. The association between sympathy and prosocial behavior was in general stronger among Western than among South-East Asian children. It is possible that the normative factors mentioned above (e.g., status of the victim, face saving, shyness reaction) may have inhibited spontaneous prosocial behavior in the children from the two social-oriented cultures even though they experienced sympathy.

The general negative relation between self-focused distress and prosocial behavior was also moderated by culture. While a negative relation occurred for the German, Israeli, as well as for the Indonesian children, no significant relation occurred for the Malaysian children. However, due to the very low occurrence and variance of prosocial behavior in the Malaysian children, this result might be a methodological artifact and therefore should be interpreted with caution.

Gender differences only occurred for the mean comparisons, and not regarding the relation between emotional reactions and prosocial behavior. German boys expressed significantly less sympathy than German girls. These gender differences are in line with the results by Kienbaum (2003) on German boys and girls using a similar design. However, these differences did not occur for the other cultural groups. For the Malaysian sample, another gender difference occurred: boys displayed stronger other-focused distress than their female counterparts. The inconsistent pattern of gender differences is in line with results on young children in Western studies (Eisenberg et al., 1988; Eisenberg \& Miller, 1987). It can be assumed that gender differences become more pronounced in older children and even more pronounced when assessing prosocial behavior by self-reports.

\section{Limitations}

According to methodological requirements in cross-cultural studies, we tried to ensure construct and method equivalence for all four cultural groups. However, it is impossible to control all possibly influential factors in one design. We aimed to create familiarity between the child and the play partner. However, since we did not assess how the children perceived the play partner, we cannot exclude cultural differences with respect to the quality of the familiarity with the play partner.

The personality of the respective play partner may also play a role. Even though all play partners were trained for the role, their personal characteristics may affect the quality of their behavior in the interaction with the child.

Furthermore, the play partner may have been perceived by Indonesian and Malaysian children as a member of an outgroup. Especially in social-oriented cultures, the differentiation between in-group and out-group members is important (Chen et al., 2002; Triandis, 1995). Helping in-group members is seen as an essential part of one's duties in social-oriented 
cultures, while out-group membership limits the scope of one's obligations to help (Baron \& Miller, 2000). In-group membership is less relevant in individual-oriented cultures and should therefore affect prosocial behavior to a lesser extent. Accordingly, in further research the relationship between the victim and the child should be varied, including horizontal relations between same-aged peers in an informal in-group. However, it is nearly impossible to train 5-year old children to play the role of a victim in a consistent manner for the whole series of such an experiment; only older children would fulfill such requirements (see for example Friedlmeier, 1993; Kobayashi, 1995).

A further necessity for future research is the observation of children in their natural everyday interactions in preschool and to register the situation-specific occurrence of prosocial behavior over a more extended time period. This method allows capturing the impact of natural interactions on prosocial behavior (Persson, 2005).

Another limitation of the design is that we could not empirically control the children's familiarity with a sad expression of an adult play partner. On the one hand, Indonesians (Javanese and Sundanese) highly value self-control and control of the expression of negative emotions, since this indicates proper behavior of a "mature" person (Magnis-Suseno, 1997; Mulder, 1992). On the other hand, differences in the experience of negative emotions between persons from individual- and social-oriented cultures mainly relate to socially disengaged, negative emotions like anger or contempt (Trommsdorff, 2006a). Therefore, children in social-oriented and individual-oriented cultures may experience an adult's expression of sadness in a similar way, at least more similar as compared to expressions of anger or contempt.

Finally, the coding of the emotional expression across the two minutes and the independent coding of the prosocial initiatives do not allow a causal analysis specifying whether emotional reactions precede, follow, or accompany the prosocial behavior. However, in line with other theoretical approaches on the relation between emotions and prosocial behavior (e.g., Eisenberg, 1986), we assume that the appraisal of a situation may evoke certain emotional reactions which may affect prosocial behavior. Therefore, further cross-cultural studies should focus on sequential analyses in order to empirically test the processes of emotion-based prosocial behavior more specifically.

\section{Conclusions}

To summarize, the strength of the present study is that it provides insight into the nature and function of emotional responding and prosocial behavior of preschool children in a specific experimental situation in different cultural contexts. The results of this study support the need to further study the conditions for prosocial behavior, including the stimulation of emotional reactions such as sympathy or distress when perceiving another person in need. Furthermore, the results show differences of children's behavior in different cultural contexts. The strength of positive relations between sympathy and prosocial behavior in young children is moderated by culture. The interpretation of these culture-specific relations between emotions and prosocial behavior is difficult since different cultural meanings may be implied. Thus, the culture-specific meaning of emotion eliciting situations as well as the socialization practices in regard to prosocial behavior (Trommsdorff \& Kornadt, 2003) have to be taken into account in future studies for a better understanding of the development of prosocial behavior. Future cross-cultural studies may also include different developmental age groups in order to test to what degree older children's behavior is guided by the cultural norms and values assumed to be relevant for the preschool children in our study.

\section{References}

Banerjee, M., \& Fielding, J. (1997). Interpreting kappa values for two-observer nursing diagnosis data. Research in Nursing and Health, 20, 465-470.

Baron, J., \& Miller, J.G. (2000). Limiting the scope of moral obligations to help: A cross-cultural investigation. Fournal of Cross-Cultural Psychology, 31, 703-725.

Bierhoff, H.W. (2002). Prosocial behaviour. Hove, UK: Psychology Press.

Bischof-Köhler, D. (1991). The development of empathy in infants. In M.E. Lamb \& H. Keller (Eds.), Infant development: Perspectives from Germanspeaking countries (pp. 245-273). Hillsdale, NJ: Lawrence Erlbaum Associates.

Chapman, M., Zahn-Waxler, C., Cooperman, G., \& Iannotti, R. (1987). Empathy and responsibility in the motivation of children's helping. Developmental Psychology, 23, 140-145.

Chen, X., Liu, M., Rubin, K.H., Cen, G., Gao, X., \& Li, D. (2002). Sociability and prosocial orientation as predictors of youth adjustment: A seven-year longitudinal study in a Chinese sample. International fournal of Behavioral Development, 26, 128-136.

Cohen, J. (1968). Weighted kappa: Nominal scale agreement with provision for scaled disagreement or partial credit. Psychological Bulletin, 70, 213-220.

Eisenberg, N. (1986). Altruistic emotion, cognition, and behavior. Hillsdale, NJ: Lawrence Erlbaum Associates.

Eisenberg, N. (1992). The caring child. Cambridge, MA: Harvard University Press.

Eisenberg, N. (1995). Prosocial development: A multifaceted model. In W.M. Kurtines \& J.L. Gewirtz (Eds.), Moral development: An introduction (pp. 401-429). Boston: Allyn \& Bacon.

Eisenberg, N., \& Fabes, R.A. (1998). Prosocial development. In W. Damon \& N. Eisenberg (Eds.), Handbook of child psychology:Vol. 3. Social, emotional, and personality development (5th ed., pp. 701-778). New York: Wiley.

Eisenberg, N., Fabes, R.A., Miller, P.A., Fultz, J., Shell, R., Mathy, R.M., \& Reno, R.R. (1989). Relation of sympathy and personal distress to prosocial behavior: A multimethod study. Fournal of Personality and Social Psychology, 57, 55-66.

Eisenberg, N., Liew, J., \& Pidada, S.U. (2004). The longitudinal relations of regulation and emotionality to quality of Indonesian children's socioemotional functioning. Developmental Psychology, 40, 790-804.

Eisenberg, N., McCreath, H., \& Ahn, R. (1988). Vicarious emotional responsiveness and prosocial behavior: Their interrelations in young children. Personality E Social Psychology Bulletin, 14, 298-311.

Eisenberg, N., \& Miller, P.A. (1987). The relation of empathy to prosocial and related behaviors. Psychological Bulletin, 10, 91-119.

Essau, C. (1992). Primary-secondary control and coping: A cross-cultural comparison. Regensburg: Roderer.

Essau, C.A., \& Trommsdorff, G. (1996). Coping with university-related problems: A cross-cultural comparison. Fournal of Cross-Cultural Psychology, 27, 315-328.

Friedlmeier, W. (1993). Empathie, Selbstkonzept und prosoziales Handeln in der mittleren Kindheit [Empathy, self-concept, and prosocial behavior in middle childhood]. Konstanz, Germany: Hartung-Gorre.

Friedlmeier, W. (1996). The development of the relationship between empathy and helping behavior in boys' middle childhood. Polish Quarterly of Developmental Psychology, 2, 17-36.

Friedlmeier, W. (2003). Empathy. In J.R. Miller, R.M. Lerner, L.B. Schiamberg, \& P.M. Anderson (Eds.), Human ecology: An encyclopedia of children, families, communities, and environments (pp. 209-215). Santa Barbara, CA: ABC-Clio.

Friedlmeier, W., \& Trommsdorff, G. (1999). Emotion regulation in early childhood: A cross-cultural comparison between German and Japanese toddlers. Fournal of Cross-Cultural Psychology, 30, 684-711.

Hoffman, M.L. (2000). Empathy and moral development: Implications for caring and justice. Cambridge, UK: Cambridge University Press.

Hofstede, G.H. (2000). Culture's consequences: International differences in workrelated values ( 5 th ed.). Newbury Park, CA: Sage.

Hofstede, G.H. (2001). Culture's consequences: Comparing values, behaviors, institutions and organizations across nations (2nd ed.). Thousand Oaks, CA: Sage. 
Inglehart, R. (1990). Culture shift in advanced industrial society. Princeton, NJ: Princeton University Press.

Kağ tçıbaşı C. (2005). Autonomy and relatedness in cultural context. Implications for self and family. Fournal of Cross-Cultural Psychology, 36, 403-422.

Kienbaum, J. (1993). Empathisches Mitgefühl und prosoziales Verhalten deutscher und sowjetischer Kindergartenkinder [Empathy and prosocial behavior of German and Russian preschool-age children]. Regensburg: Roderer.

Kienbaum, J. (2003). Entwicklungsbedingungen prosozialer Responsivität in der Kindheit. Eine Analyse der Rolle von kindlichem Temperament und der Sozialisation innerhalb und außerhalb der Familie [Developmental conditions of prosocial responsivity in childhood. An analysis of the role of child temperament and socialization within and outside the family]. Lengerich, Germany: Pabst Science.

Kobayashi, M. (1995). Selbstkonzept und Empathie im Kulturvergleich: Ein Verglich deutscher und japanischer Kinder [Self-concept and empathy in cross-cultural psychology: A comparison between German and Japanese Children]. Konstanz, Germany: Universitätsverlag Konstanz.

MacDonald, K.B. (1984). An ethological-social learning theory of the development of altruism: Implications for human sociobiology. Ethology and Sociobiology, 5, 97-109.

Magnis-Suseno, F. (1997). Favanese ethics and world view. The favanese idea of the good life. Jakarta, Indonesia: Gramedia Pustaka Utama.

Markus, H.R., \& Kitayama, S. (1991). Culture and the self: Implications for cognition, emotion, and motivation. Psychological Review, 98, 224-253.

Markus, H.R., \& Kitayama, S. (1994). The cultural construction of self and emotion: Implications for social behavior. In S. Kitayama \& H.R. Markus (Eds.), Emotion and culture: Empirical studies of mutual influence (pp. 89-130). Washington, DC: American Psychological Association.

Matsumoto, D.R. (2000). Culture and psychology: People around the world. Belmont, CA: Wadsworth.

Mesquita, B., Frijda, N.H., \& Scherer, K.R. (1997). Culture and emotion. In J.W. Berry \& P.R. Dasen (Eds.), Handbook of cross-cultural psychology: Vol. 2. Basic processes and human development (2nd ed., pp. 255-297). Needham Heights, MA: Allyn \& Bacon.

Mesquita, B., \& Markus, H.R. (2004). Culture and emotion. Models of agency as sources of cultural variation in emotion. In A.S.R. Manstead, N. Frijda, \& A. Fischer (Eds.), Feelings and Emotions. The Amsterdam Symposium (pp. 341-358). Cambridge, NY: Cambridge University Press.

Miller, J.G. (1997). Cultural conceptions of duty: Implications for motivation and morality. In D. Munro, J.F. Schumaker, \& S. Carr (Eds.), Motivation and culture (pp. 178-192). New York: Routledge.

Miller, P.A., Kozu, J., \& Davis, A.C. (2001). Social influence, empathy, and prosocial behavior in cross-cultural perspective. In W. Wosinska, R.B. Cialdini, D.W. Barrett, \& J. Reykowski (Eds.), The practice of social influence in multiple cultures. Applied social research series (pp. 63-77). Mahwah, NJ: Erlbaum.

Mulder, N. (1992). Individual and society in fava: A cultural analysis. Yogyakarta, Indonesia: Gadjah Mada University Press.

Oyserman, D., Coon, H.M., \& Kemmelmeier, M. (2002). Rethinking individualism and collectivism: Evaluation of theoretical assumptions and metaanalyses. Psychological Bulletin, 128, 3-72.

Persson, G.E.B. (2005). Developmental perspectives on prosocial and aggressive motives in preschoolers' peer interactions. International fournal of Behavioral Development, 29, 80-91.
Rogoff, B. (2003). The cultural nature of human development. Oxford: Oxford University Press.

Rothbaum, F., Pott, M., Azuma, H., Miyake, K., \& Weisz, J. (2000). The development of close relationships in Japan and the United States: Paths of symbiotic harmony and generative tension. Child Development, 71, 1121-1142.

Rothbaum, F., \& Trommsdorff, G. (2004). Do roots and wings complement or oppose one another? The socialization of relatedness and autonomy in cultural context. In J.E. Grusec \& P. Hastings (Eds.), The handbook of socialization (pp. 481-489). New York: The Guilford Press.

Schwartz, S.H., Struch, N., \& Bilsky, W. (1990). Values and intergroup social motives: A study of Israeli and German students. Social Psychology Quarterly, 53, 185-198.

Staub, E. (1979). Positive social behavior and morality: Vol. 2. Socialization and development. New York: Academic Press.

Strayer, J., \& Roberts, W. (1989). Children's empathy and role taking: Child and parental factors, and relations to prosocial behavior. Fournal of Applied Developmental Psychology, 10, 227-239.

Super, C.M., \& Harkness, S. (1997). The cultural structuring of child development. In J.W. Berry, P.R. Dasen, \& T.S. Saraswathi (Eds.), Handbook of crosscultural psychology: Vol. 2. Basic processes and human development (2nd ed., pp. 1-39). Boston: Allyn \& Bacon.

Triandis, H.C. (1995). Individualism and collectivism. Boulder, CO: Westview.

Trommsdorff, G. (1995). Person context relations as developmental conditions for empathy and prosocial action: A cross-cultural analysis. In T.A. Kindermann \& J. Valsiner (Eds.), Development of person-context relations (pp. 113-146). Hillsdale, NJ: Erlbaum.

Trommsdorff, G. (2005). Entwicklung sozialer Motive: Pro- und antisoziales Handeln [Development of social motives: prosocial and antisocial behavior]. In J.B. Asendorpf (Hrsg.), „Soziale, emotionale und Persönlichkeitsentwicklung”. Enzyklopädie Serie V, Band 3 (pp. 75-139). Göttingen: Hogrefe.

Trommsdorff, G. (2006a). Development of emotions as organized by culture. International Society for the Study of Behavioural Development. Newsletter, 49, 1-4.

Trommsdorff, G. (2006b). Parent-child relations over the life-span. A crosscultural perspective. In K.H. Rubin \& O.B. Chung (Eds.), Parenting beliefs, behaviors, and parent-child relations. A cross-cultural perspective (pp. 143-183). New York: Psychology Press.

Trommsdorff, G. (in press). Intergenerational relations and cultural transmission. In U. Schönpflug (Ed.), Perspectives on cultural transmission. Oxford: Oxford University Press.

Trommsdorff, G., \& Kornadt, H.-J. (2003). Parent-child relations in crosscultural perspective. In L. Kuczynski (Ed.), Handbook of dynamics in parent-child relations (pp. 271-306). London: Sage.

Whiting, B.B., \& Whiting, J.W. (1975). Children of six cultures: A psycho-cultural analysis. Cambridge, MA: Harvard University Press.

Young, S.K., Fox, N.A., \& Zahn-Waxler, C. (1999). The relations between temperament and empathy in 2-year-olds. Developmental Psychology, 35, 1189-1197.

Zahn-Waxler, C., Radke-Yarrow, M., \& King, R.A. (1979). Child rearing and children's initiations toward victims of distress. Child Development, 50, 319-330.

Zahn-Waxler, C., Radke-Yarrow, M., \& Wagner, E. (1992). Development of concern for others. Developmental Psychology, 28, 126-136. 